\title{
Parametric Instability of Square Laminated Plates in Hygrothermal Environment
}

\author{
Manoj Kumar Rath and Shishir Kumar Sahu \\ Department of Civil Engineering, National Institute of Technology, Rourkela, Orissa 769008, India \\ Correspondence should be addressed to Shishir Kumar Sahu; rssksahu@yahoo.com
}

Received 29 April 2013; Accepted 8 July 2013

Academic Editor: Mustafa Kemal Apalak

Copyright ( 2013 M. K. Rath and S. K. Sahu. This is an open access article distributed under the Creative Commons Attribution License, which permits unrestricted use, distribution, and reproduction in any medium, provided the original work is properly cited.

\begin{abstract}
The present paper investigates the parametric instability of square laminated plates subjected to periodic dynamic loadings in hygrothermal environment. The effects of various parameters like the increase in static load factor and the degree of orthotropy of simply supported composite plates at elevated temperatures and moisture concentrations on the principal instability regions are investigated using finite element method. The effects of transverse shear deformation and rotary inertia are used to study the antisymmetric angle-ply square plates. A simple laminated plate model is developed for the parametric instability of square laminated plates subjected to hygrothermal loading. A computer program based on FEM in MATLAB environment is developed to perform all necessary computations. The results show that instability of square laminated plates occurs for different parameters with an increase in temperature and moisture environment. The onset of instability occurs earlier, and the width of dynamic instability regions increases with a rise in temperature and moisture for different parameters. The effect of damping shows that there is a finite critical value of dynamic load factor for each instability region below which the square laminated plates cannot become unstable.
\end{abstract}

\section{Introduction}

There is a tremendous increase in the utilization of composite materials in thin-walled structural components of high speed aircrafts, submarines, automobiles and other high-performance application areas. When exposed to high temperature and moisture, the changes in vibration and static and dynamic stability characteristics have necessitated a strong need to understand their dynamic behavior under different loading conditions.

L. W. Chen and Y. M. Chen [1] studied the free vibration of the laminated rectangular composite plate exposed to steady state hygrothermal environment using finite element method. Sai Ram and Sinha [2] investigated the effects of moisture and temperature on the free vibration of laminated composite plates using finite element method. Huang et al. [3] discussed the effects of hygrothermal conditions on the dynamic response of shear deformable laminated plates resting on elastic foundations using a micro-to-micromechanical analytical model. Thangaratnam et al. [4] studied the buckling analysis of composite laminates for critical temperature.
The mathematical formulation is based on linear theory and the finite element method using semiloof elements. Ram and Sinha [5] investigated the effects of moisture and temperature on the static stability of laminated composite plates. The mathematical model is based on finite element method which takes transverse shear deformation into account. Patel et al. [6] studied the hygrothermal buckling effects on the structural behavior of thick composite laminates using higherorder theory. The analysis is carried out employing a $\mathrm{C}^{0}$ QUAD-8 isoparametric higher-order finite element.

Few studies are available on the behavior of composite plates under ambient temperature and moisture subjected to in-plane loads. Srinivasan and Chellapandi [7] studied the dynamic stability of rectangular plates due to periodic in-plane load by using finite strip method. Lien-Wen and Jenq-Yiing [8] investigated the dynamic stability of laminated composite plates by Galerkin finite element method. Kwon [9] examined the dynamic instability of layered composite plates by finite element method by using higher-order bending theory. Balamurugan et al. [10] studied the nonlinear dynamic instability of laminated composite plates using finite 
element model. Patel et al. [11] investigated the dynamic instability of laminated composite plates supported on elastic foundations and subjected to periodic in-plane loads, using $\mathrm{C}^{1}$ eight-nodded shear-flexible plate element. Sahu and Datta [12] presented the dynamic stability behavior of laminated composite curved panels subjected to in-plane static and periodic compressive loads using finite element method. The boundaries of instability region were obtained using Bolotin's method and were represented in amplitude-excitation frequency plane.

\section{Mathematical Formulation}

The mathematical formulation for parametric instability behavior of laminated composite plates subjected to moisture and temperature is presented. Consider a laminated plate of uniform thickness " $t$ " consisting of a number of thin laminae, each of which may be arbitrarily oriented at an angle " $\theta$ " with reference to the $x$-axis of the coordinate system as shown in Figures 1 and 2.

2.1. Governing Equations. The governing differential equations for vibration of a shear deformable laminated composite plates and shells in general are specified here, but the scope of the analysis is for composite plates. The woven fiber laminated composite plates in hygrothermal environment derived on the basis of first order shear deformation theory and (FSDT) subjected to in-plane loads are employed, and a shear correction factor of 5/6 is included for all the numerical computations as follows:

$$
\begin{aligned}
& \frac{\partial N_{x}}{\partial x}+\frac{\partial N_{x y}}{\partial y}-\frac{1}{2}\left(\frac{1}{R_{y}}-\frac{1}{R_{x}}\right) \frac{\partial M_{x y}}{\partial y}+\frac{Q_{x}}{R_{x}}+\frac{Q_{y}}{R_{x y}} \\
& =P_{1} \frac{\partial^{2} u}{\partial t^{2}}+P_{2} \frac{\partial^{2} \theta_{x}}{\partial t^{2}} \\
& \frac{\partial N_{x y}}{\partial x}+\frac{\partial N_{y}}{\partial y}+\frac{1}{2}\left(\frac{1}{R_{y}}-\frac{1}{R_{x}}\right) \frac{\partial M_{x y}}{\partial x}+\frac{Q_{y}}{R_{y}}+\frac{Q_{x}}{R_{x y}} \\
& =P_{1} \frac{\partial^{2} v}{\partial t^{2}}+P_{2} \frac{\partial^{2} \theta_{y}}{\partial t^{2}}, \\
& \frac{\partial Q_{x}}{\partial x}+\frac{\partial Q_{y}}{\partial y}-\frac{N_{x}}{R_{x}}-\frac{N_{y}}{R_{y}}-2 \frac{N_{x y}}{R_{x y}}+N_{x}^{a} \frac{\partial^{2} w}{\partial x^{2}} \\
& +N_{y}^{a} \frac{\partial^{2} w}{\partial y^{2}}+N_{x y}^{a} \frac{\partial^{2} w}{\partial x \partial y}=P_{1} \frac{\partial^{2} w}{\partial t^{2}} \\
& \frac{\partial M_{x}}{\partial x}+\frac{\partial M_{x y}}{\partial y}-Q_{x}=P_{3} \frac{\partial^{2} \theta_{x}}{\partial t^{2}}+P_{2} \frac{\partial^{2} u}{\partial t^{2}} \\
& \frac{\partial M_{x y}}{\partial x}+\frac{\partial M_{y}}{\partial y}-Q_{y}=P_{3} \frac{\partial^{2} \theta_{y}}{\partial t^{2}}+P_{2} \frac{\partial^{2} v}{\partial t^{2}}
\end{aligned}
$$

where $N_{x}, N_{y}$, and $N_{x y}$ are the in-plane stress resultants, $M_{x}, M_{y}$, and $M_{x y}$ are moment resultants and $Q_{x}$ and $Q_{y}$ are transverse, shear stress resultants. $R_{x}, R_{y}$, and $R_{x y}$ identify

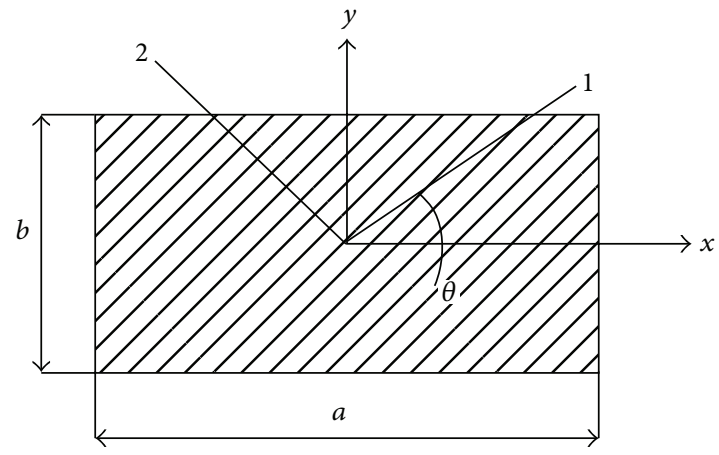

FIgURE 1: Arbitrarily oriented laminated plate.

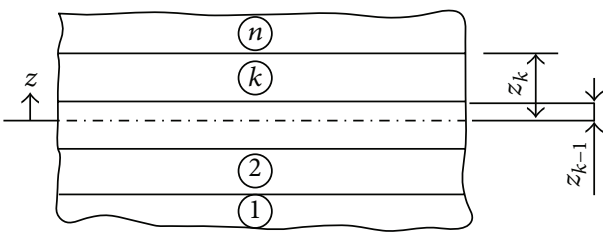

FIGURE 2: Geometry of an $n$-layered laminate.

the radii of curvatures in the $x$ and $y$ directions and radius of twist.

$$
\left(P_{1}, P_{2}, P_{3}\right)=\sum_{k=1}^{n} \int_{z_{k-1}}^{z_{k}}(\rho)_{k}\left(1, z, z^{2}\right) d z,
$$

where $P_{1}, P_{2}$, and $P_{3}$ are the applied in-plane load.

The self-explanatory figure in Figure 3.

2.2. Dynamic Stability Studies. The equation of motion for vibration of a laminated composite panel in hygrothermal environment, subjected to generalized in-plane load. $N(t)$ can be expressed in the matrix form as follows:

$$
[M]\{\ddot{q}\}+\left[\left[K_{e}\right]-N(t)\left[K_{g}\right]\right]\{q\}=0 .
$$

" $q$ " is the vector of degrees of freedoms $\left(u, v, w, \theta_{x}, \theta_{y}\right)$. The in-plane load " $N(t)$ " may be harmonic and can be expressed in the following form:

$$
N(t)=N_{s}+N_{t} \cos \Omega t,
$$

where $N_{s}$ is the static portion of load $N(t), N_{t}$ is the amplitude of the dynamic portion of $N(t)$, and $\Omega$ is the frequency of the excitation. The stress distribution in the panel may be periodic. Considering the static and dynamic components of load as a function of the critical load, as gets

$$
N_{s}=\alpha N_{\text {cr }}, \quad N_{t}=\beta N_{\text {cr }},
$$

where $\alpha$ and $\beta$ are the static and dynamic load factors, respectively. Using (5), the equation of motion for panel in hygrothermal environment under periodic loads in matrix form may be obtained as follows:

$$
[M]\{\ddot{q}\}+\left[\left[K_{e}\right]-\alpha N_{\mathrm{cr}}\left[K_{g}\right]-\beta N_{\mathrm{cr}}\left[K_{g}\right] \cos \Omega t\right]\{q\}=0 .
$$




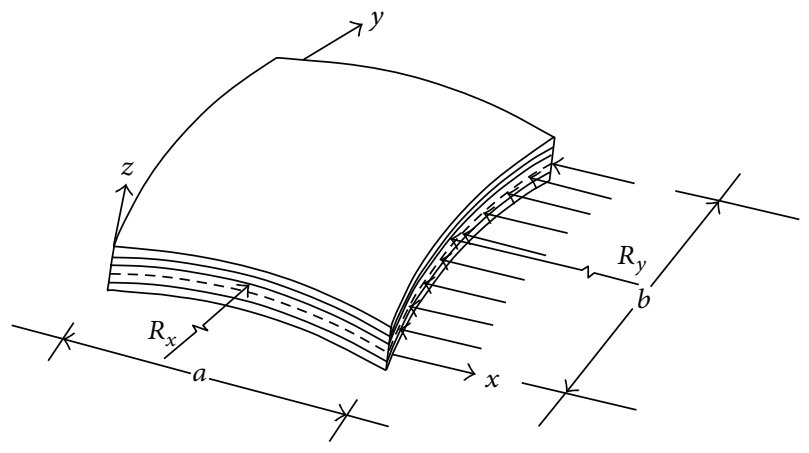

FIGURE 3: Laminated composite curved panels under in-plane harmonic loading under hygrothermal environment.

Equation (6) represents a system of differential equations with periodic coefficients of the Mathieu-Hill type. The development of regions of instability arises from Floquet's theory which establishes the existence of periodic solutions of periods $T$ and $2 T$. The boundaries of the primary instability regions with period $2 T$, where $T=2 \pi / \Omega$, are of practical importance, and the solution can be achieved in the form of the trigonometric series

$$
q(t)=\sum_{k=1,3,5, \ldots}^{\infty}\left[\left\{a_{k}\right\} \sin \left(\frac{k \Omega t}{2}\right)+\left\{b_{k}\right\} \cos \left(\frac{k \Omega t}{2}\right)\right] .
$$

Putting this in (6) and if only the first term of the series is considered, equating coefficients of $\sin (\Omega t / 2)$ and $\cos (\Omega t / 2)$, (6) reduces to

$$
\left[\left[K_{e}\right]-\alpha P_{\mathrm{cr}}\left[K_{g}\right] \pm \frac{1}{2} \beta P_{\mathrm{cr}}\left[K_{g}\right]-\frac{\Omega^{2}}{4}[M]\right]\{q\}=0 .
$$

Equation (8) represents an eigenvalue problem for known values of $\alpha, \beta$, and $P_{\mathrm{cr}}$. The two conditions under the plus and minus signs correspond to two boundaries (upper and lower) of the dynamic instability region. The above eigenvalue solution give of $\Omega$, which gives the boundary frequencies of the instability regions for the given values of $\alpha$ and $\beta$. In this analysis, the computed static buckling load of the panel is considered as the reference load. Before solving the above equations, the stiffness matrix $[K]$ is modified through imposition of boundary conditions.

2.3. Constitutive Relation. The constitutive relations for the plate subjected to moisture and temperature are

$$
\{F\}=[D]\{\varepsilon\}-\left\{F^{N}\right\},
$$

where

$$
\begin{gathered}
\{F\}=\left\{N_{x}, N_{y}, N_{x y}, M_{x}, M_{y}, M_{x y}, Q_{x}, Q_{y}\right\}^{T}, \\
\left\{F^{N}\right\}=\left\{N_{x}^{N}, N_{y}^{N}, N_{x y}, M_{x}^{N}, M_{y}^{N}, M_{x y}^{N}, 0,0\right\}^{T}, \\
\{\varepsilon\}=\left\{\varepsilon_{x}, \varepsilon_{y}, \gamma_{x y}, K_{x}, K_{y}, K_{x y}, \varphi_{x}, \varphi_{y}\right\}^{T},
\end{gathered}
$$

TABLE 1: Elastic moduli of glass fiber/epoxy lamina at different temperatures. $\alpha_{1}=-0.3 \times 10^{-6} /{ }^{\circ} \mathrm{K}, \alpha_{2}=28.1 \times 10^{-6} /{ }^{\circ} \mathrm{K}, \beta_{1}=0, \beta_{2}=$ 0.44 .

\begin{tabular}{lcccccc}
\hline \multirow{2}{*}{ Elastic moduli } & \multicolumn{7}{c}{ Temperature in (K) } \\
& 300 & 325 & 350 & 375 & 400 & 425 \\
\hline$E_{1}$ & 7.9 & 7.6 & 7.1 & 6.7 & 6.5 & 6.3 \\
$E_{2}$ & 7.4 & 6.8 & 6.4 & 6.2 & 5.9 & 5.7 \\
$G_{12}$ & 2.9 & 2.6 & 2.3 & 2.1 & 1.8 & 1.6 \\
$v_{12}$ & 0.4 & 0.43 & 0.41 & 0.35 & 0.36 & 0.35 \\
\hline
\end{tabular}

where $N_{x}, N_{y}$, and $N_{x y}$ are in-plane internal stress resultants, $M_{x}, M_{y}$, and $M_{x y}$ are internal moment resultants, $Q_{x}, Q_{y}$ are transverse shear resultants, $N_{x}^{N}, N_{y}^{N}$, and $N_{x y}^{N}$ are inplane non-mechanical stress resultants due to moisture and temperature, $M_{x}^{N}, M_{y}^{N}$, and $M_{x y}^{N}=$ non-mechanical moment resultants due to moisture and temperature, $\varepsilon_{x}, \varepsilon_{y}$, and $\gamma_{x y}=$ in-plane strains of the midplane, $K_{x}, K_{y}$, and $K_{x y}$ are curvature of the plate, and $\varphi_{x}, \varphi_{y}$ are Shear rotations in $x z$ and $y z$ planes, respectively.

Element stiffness matrix is given by

$$
\left[K_{e}\right]=\int_{-1}^{+1} \int_{-1}^{+1}[B]^{T}[D][B]|J| d \xi d \eta
$$

The geometric stiffness matrix due to residual stresses is given by

$$
\left[K_{G e}^{r}\right]=\int_{-1}^{+1} \int_{-1}^{+1}[G]^{T}[S][G]|J| d \xi d \eta
$$

The geometric stiffness matrix due to applied in-plane loads is given by

$$
\left[K_{G e}^{a}\right]=\int_{-1}^{+1} \int_{-1}^{+1}[H]^{T}[P][H]|J| d \xi d \eta .
$$

The element load vector due to the hygrothermal forces and moments is given by

$$
\left\{P_{e}^{N}\right\}=\int_{-1}^{+1} \int_{-1}^{+1}[B]^{T}\left\{F^{N}\right\}|J| d \xi d \eta
$$

\section{Results and Discussion}

The geometrical and material properties of the laminated composite plates are $a=b=0.235 \mathrm{~m}, h=0.006 \mathrm{~m}$ (unless otherwise stated). The material properties obtained from tensile testing of glass/epoxy composite plates at different temperatures and moisture are as shown in Tables 1 and 2.

The nondimensional excitation frequency $\Omega=$ $\left.\bar{\Omega} a^{2} \sqrt{\left(\rho / E_{22}\right.} h^{2}\right)$ is used throughout the dynamic instability studies, where $\bar{\Omega}$ is the excitation frequency in radian/second. The principal instability regions of woven fiber laminated composite plates subjected to in-plane periodic loads are plotted with non-dimensional frequency $\Omega / \omega$ (ratio of excitation frequency to the free vibration frequency) versus the dynamic in-plane load $\beta$. Here, a static load factor $\alpha=0.2$ 
TABLE 2: Elastic moduli of glass fiber/epoxy lamina at different moisture concentrations. $\alpha_{1}=-0.3 \times 10^{-6} /{ }^{\circ} \mathrm{K}, \alpha_{2}=28.1 \times$ $10^{-6} /{ }^{\circ} \mathrm{K}, \beta_{1}=0, \beta_{2}=0.44$.

\begin{tabular}{lccccc}
\hline \multirow{2}{*}{ Elastic moduli } & \multicolumn{5}{c}{ Moisture concentration in \% } \\
& 0.0 & 0.25 & 0.5 & 0.75 & 1.0 \\
\hline$E_{1}$ & 7.9 & 7.6 & 7.5 & 7.3 & 7.2 \\
$E_{2}$ & 7.4 & 7.4 & 7.3 & 7.1 & 7.0 \\
$G_{12}$ & 2.9 & 2.9 & 2.8 & 2.7 & 2.6 \\
$v_{12}$ & 0.4 & 0.4 & 0.4 & 0.39 & 0.39 \\
\hline
\end{tabular}

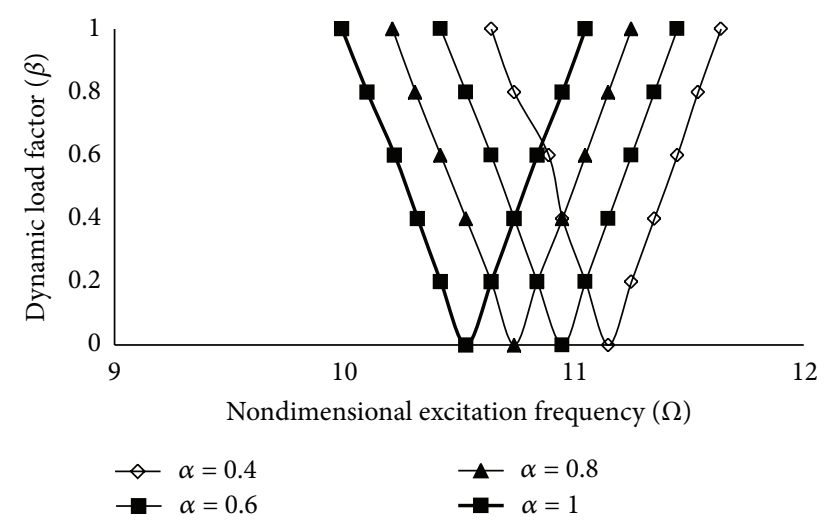

FIGURE 4: Variation of instability regions with temperature at $325 \mathrm{~K}$ for simply supported SSSS of $[45 /-45]_{4}$, woven fiber laminated composite plates.

is taken for parametric study of laminated composite plates in hygrothermal environment throughout the analysis unless otherwise stated.

The effect of increase in static load factor of eight-layered antisymmetric woven fiber laminated composite plates on non-dimensional excitation frequency is analyzed in Figures 3 , 4, and 5 with the increase of temperatures of $325 \mathrm{~K}, 375 \mathrm{~K}$, and $425 \mathrm{~K}$, respectively.

It is observed that with the increase of static load factor from 0.2 to 1 , the onset of dynamic instability occurs earlier, and the width of dynamic instability region also increases.

The variations of dynamic instability regions with increase in static in-plane loads of woven fiber composite plates with increase in moisture concentrations of $0.25 \%$, $0.5 \%$, and $1 \%$ are observed as shown in Figures 6,7 , and 8 respectively. The onset of instability occurs earlier with increase of compressive static in-plane load; the instability region tends to shift to lower frequencies and wider.

The effect of the degree of orthotropy is examined for the eight-layered anti-symmetric angle-ply laminated plates on the non-dimensional excitation frequency is presented in Figures 9, 10, and 11 with increase of temperature of $325 \mathrm{~K}$, $375 \mathrm{~K}$, and $425 \mathrm{~K}$, respectively. It is seen that with increase in the values of $E_{1} / E_{2}=10,20$, and 40 , the onset of instability occurs earlier with decrease in degree of orthotropy. The width of instability zones decreases with the increase of the degree of orthotropy in higher temperature environment.

The variations of dynamic instability regions with increase in the values of degree of orthotropy $E_{1} / E_{2}=10$,

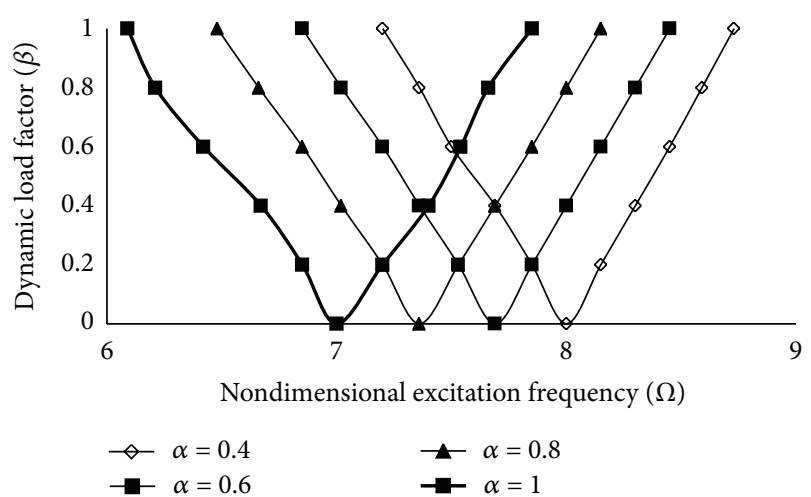

FIGURE 5: Variation of instability regions with temperature at $375 \mathrm{~K}$ for simply supported SSSS of $[45 /-45]_{4}$, woven fiber laminated composite plates.

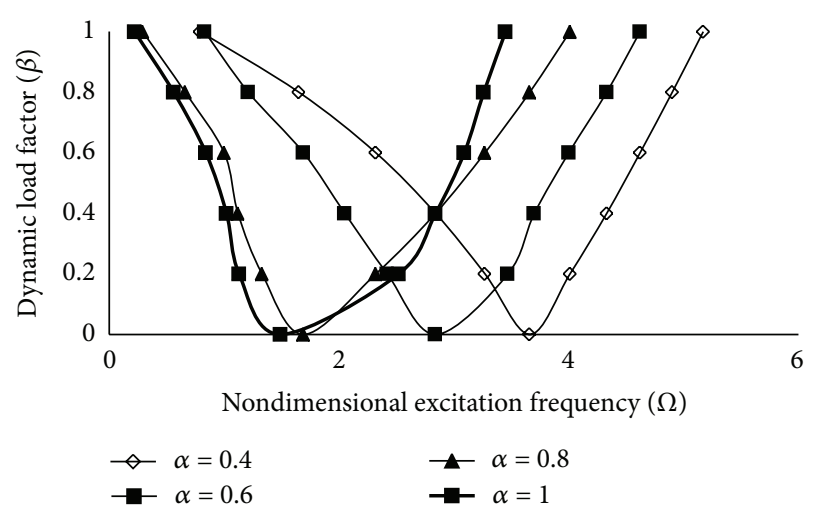

FIGURE 6: Variation of instability regions with temperature at $425 \mathrm{~K}$ for simply supported SSSS of $[45 /-45]_{4}$, woven fiber laminated composite plates.

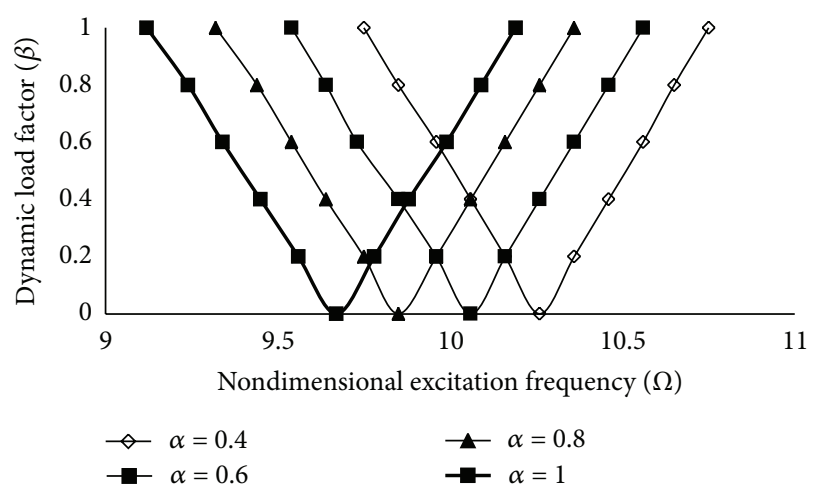

FIGURE 7: Variation of instability regions with moisture concentration at $0.25 \%$ for simply supported SSSS of $[45 /-45]_{4}$, woven fiber laminated composite plates.

20, and 40 are presented as shown in Figures 12, 13, and 14 with increase in moisture concentration of $0.25 \%, 0.5 \%$, and $1 \%$ respectively. The onset of instability occurs earlier with decrease in degree of orthotropy, with increase in orthotropy the narrow instability regions show more stiffness in higher moisture concentration environment. 


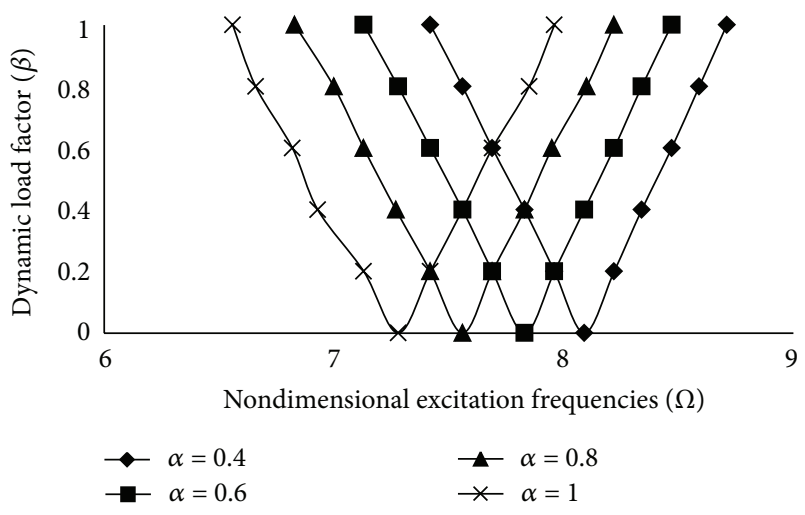

FIGURE 8: Variation of instability regions with moisture concentration at $0.5 \%$ for simply supported SSSS of $[45 /-45]_{4}$, woven fiber laminated composite plates.

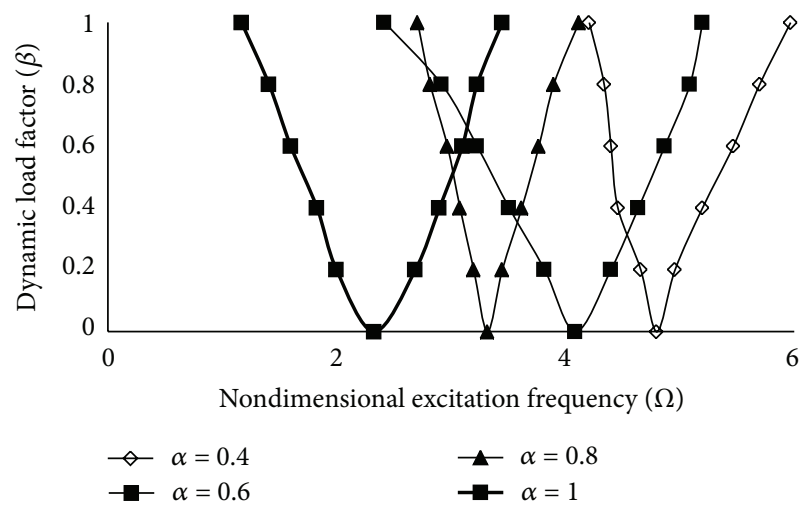

FIgURE 9: Variation of instability regions with moisture concentration at $1 \%$ for simply supported SSSS of $[45 /-45]_{4}$, woven fiber laminated composite plates.

The onset of instability for woven fiber composite is smaller than unidirectional composite because the materials properties are exist in two directions due to bending stretching coupling effect (Figure 15).

\section{Conclusions}

A parametric instability study of woven fiber laminated composite plates in hygrothermal environment subjected to periodic in-plane loads is examined. The following observation can be made.

(i) The excitation frequencies of square laminated plates decrease with the increase of temperature and moisture concentration due to reduction of stiffness for all laminates.

(ii) The greater is the static load factor, the higher is the instability region of square laminated plates in hygrothermal environment.

(iii) The increase in the degree of orthotropy is to enhance the dynamic stability strength and to shift the occurrence of instability to lower values of excitation frequencies in hygrothermal environment.

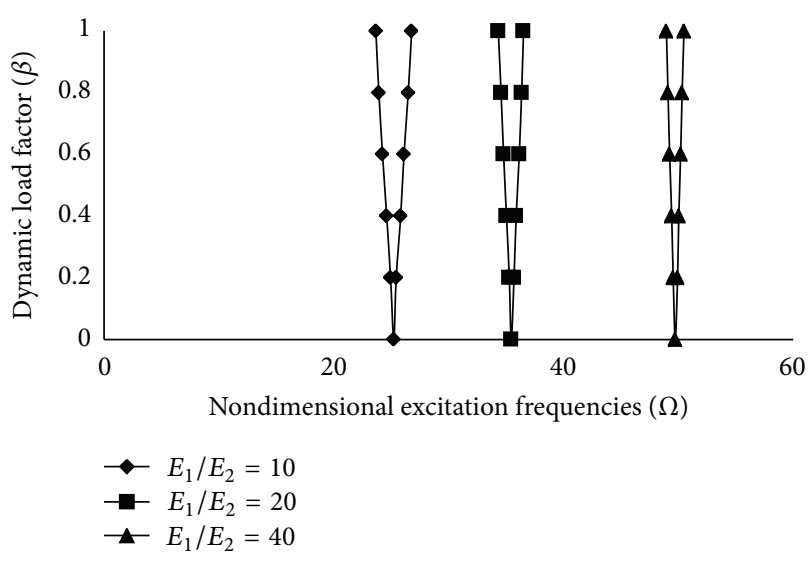

FIgURE 10: Variation of instability regions with temperature at $325 \mathrm{~K}$ for simply supported SSSS of $[45 /-45]_{4}, \alpha=0.2$, woven fiber laminated composite plates.

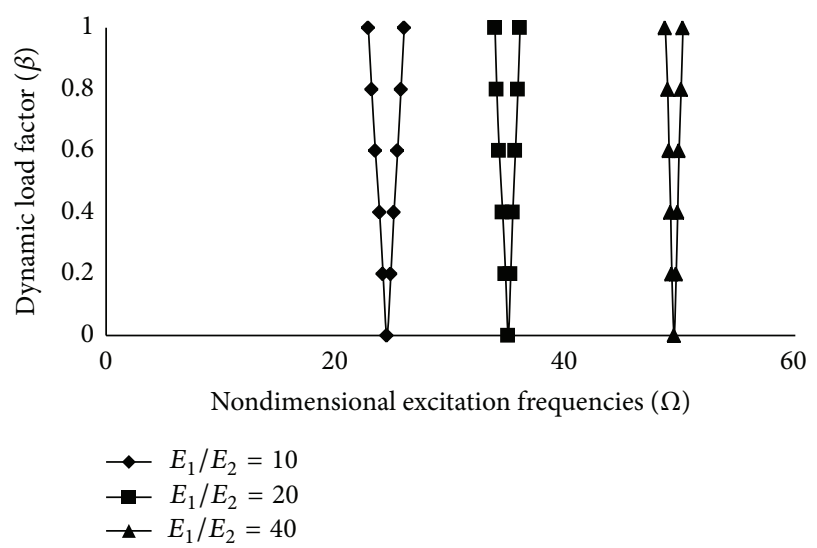

FIGURE 11: Variation of instability regions with temperature at $375 \mathrm{~K}$ for simply supported SSSS of $[45 /-45]_{4}, \alpha=0.2$, woven fiber laminated composite plates.

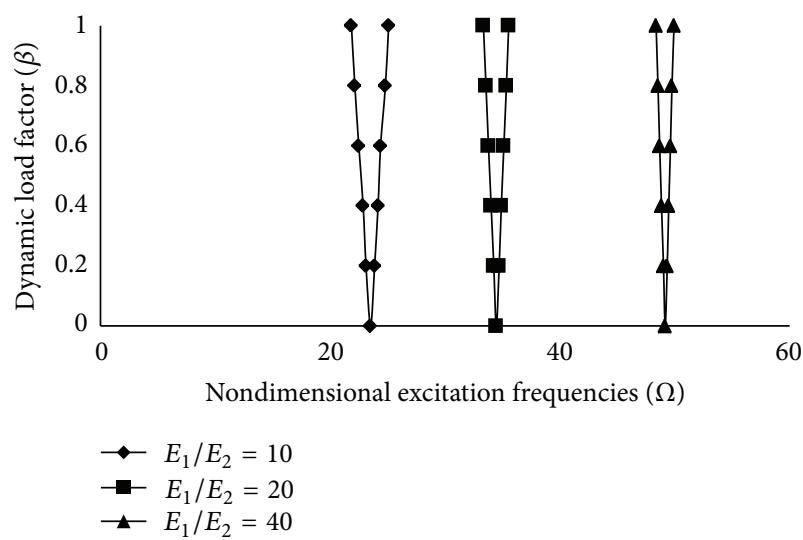

FIGURE 12: Variation of instability regions with temperature at $425 \mathrm{~K}$ for simply supported SSSS of $[45 /-45]_{4}, \alpha=0.2$, woven fiber laminated composite plates. 


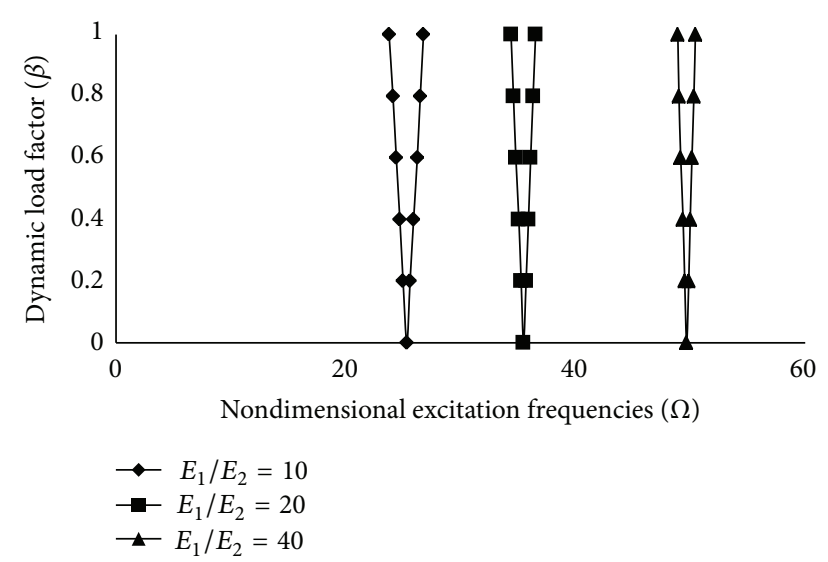

FIGURE 13: Variation of instability regions with moisture concentration at $0.25 \%$ for simply supported SSSS of $[45 /-45]_{4}, \alpha=0.2$, woven fiber laminated composite plates.

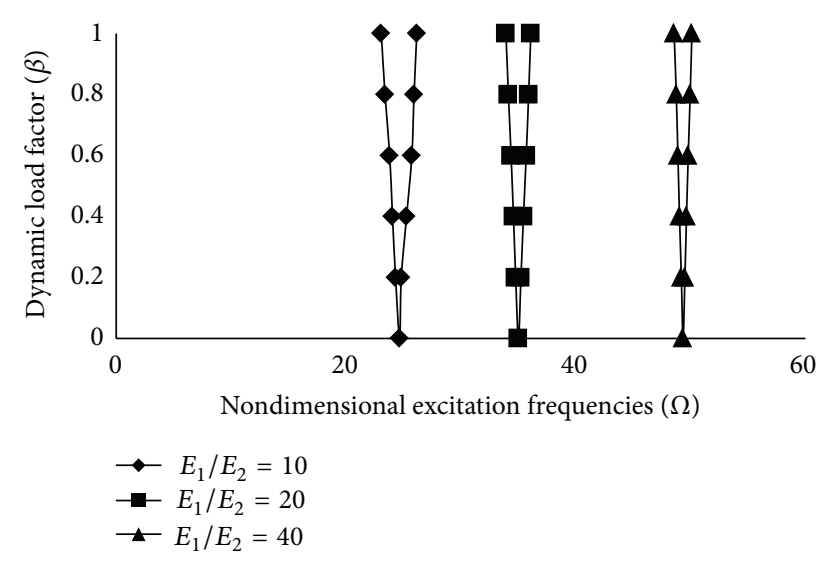

FIGURE 14: Variation of instability regions with moisture concentration at $0.5 \%$ for simply supported SSSS of $[45 /-45]_{4}, \alpha=0.2$, woven fiber laminated composite plates.

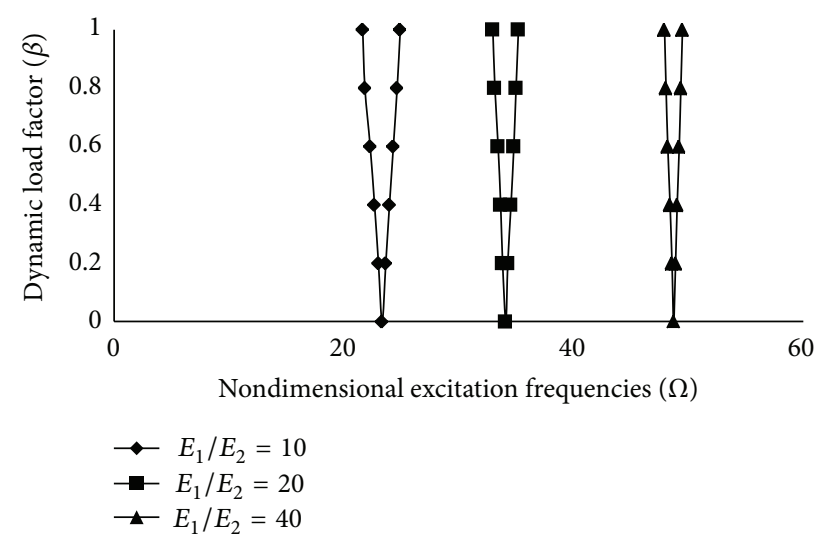

FIGURE 15: Variation of instability regions with moisture concentration at $1 \%$ for simply supported SSSS of $[45 /-45]_{4}, \alpha=0.2$, woven fiber laminated composite plates. (iv) The excitation frequencies of laminated fiber composite panels decrease with increase of temperature and moisture concentration due to reduction of stiffness for all laminates.

(v) The high-modulus-fiber material plate is most stable in hygrothermal environment.

From the present studies, it is concluded that the parametric instability of woven fiber laminated composite plates is influenced by the static load factor and degree of orthotropic. Such a property can be utilized to tailor the design of woven fiber laminated composite plates in hygrothermal environment.

\section{References}

[1] L. W. Chen and Y. M. Chen, "Vibrations of hygrothermal elastic composite plates," Engineering Fracture Mechanics, vol. 31, no. 2, pp. 209-220, 1988.

[2] K. S. S. Ram and P. K. Sinha, "Hygrothermal effects on the free vibration of laminated composite plates," Journal of Sound and Vibration, vol. 158, no. 1, pp. 133-148, 1992.

[3] X. L. Huang, H. S. Shen, and J. J. Zheng, "Nonlinear vibration and dynamic response of shear deformable laminated plates in hygrothermal environments," Composites Science and Technology, vol. 64, no. 10-11, pp. 1419-1435, 2004.

[4] K. R. Thangaratnam, P. Palaninathan, and J. Ramachandran, "Thermal buckling of composite laminated plates," Computers and Structures, vol. 32, no. 5, pp. 1117-1124, 1989.

[5] K. S. S. Ram and P. K. Sinha, "Hygrothermal effects on the buckling of laminated composite plates," Composite Structures, vol. 21, no. 4, pp. 233-247, 1992.

[6] B. P. Patel, M. Ganapathi, and D. P. Makhecha, "Hygrothermal effects on the structural behaviour of thick composite laminates using higher-order theory," Composite Structures, vol. 56, no. 1, pp. 25-34, 2002.

[7] R. S. Srinivasan and P. Chellapandi, "Dynamic stability of rectangular laminated composite plates," Computers and Structures, vol. 24, no. 2, pp. 233-238, 1986.

[8] C. Lien-Wen and Y. Jenq-Yiing, "Dynamic stability of laminated composite plates by the finite element method," Computers and Structures, vol. 36, no. 5, pp. 845-851, 1990.

[9] Y. W. Kwon, "Finite element analysis of dynamic instability of layered composite plates using a high-order bending theory," Computers and Structures, vol. 38, no. 1, pp. 57-62, 1991.

[10] V. Balamurugan, M. Ganapathi, and T. K. Varadan, "Nonlinear dynamic instability of laminated composite plates using finite element method," Computers and Structures, vol. 60, no. 1, pp. 125-130, 1996.

[11] B. P. Patel, M. Ganapathi, K. R. Prasad, and V. Balamurugan, "Dynamic instability of layered anisotropic composite plates on elastic foundations," Engineering Structures, vol. 21, no. 11, pp. 988-995, 1999.

[12] S. K. Sahu and P. K. Datta, "Dynamic stability of laminated composite curved panels with cutouts," Journal of Engineering Mechanics, vol. 129, no. 11, pp. 1245-1253, 2003. 

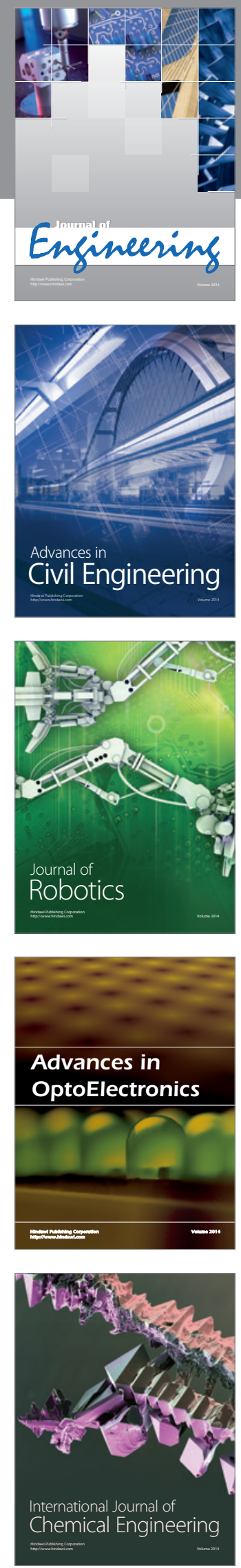

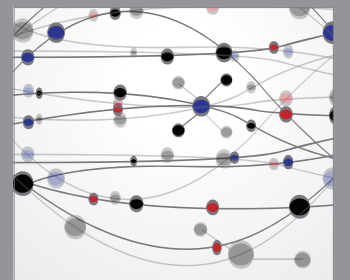

The Scientific World Journal
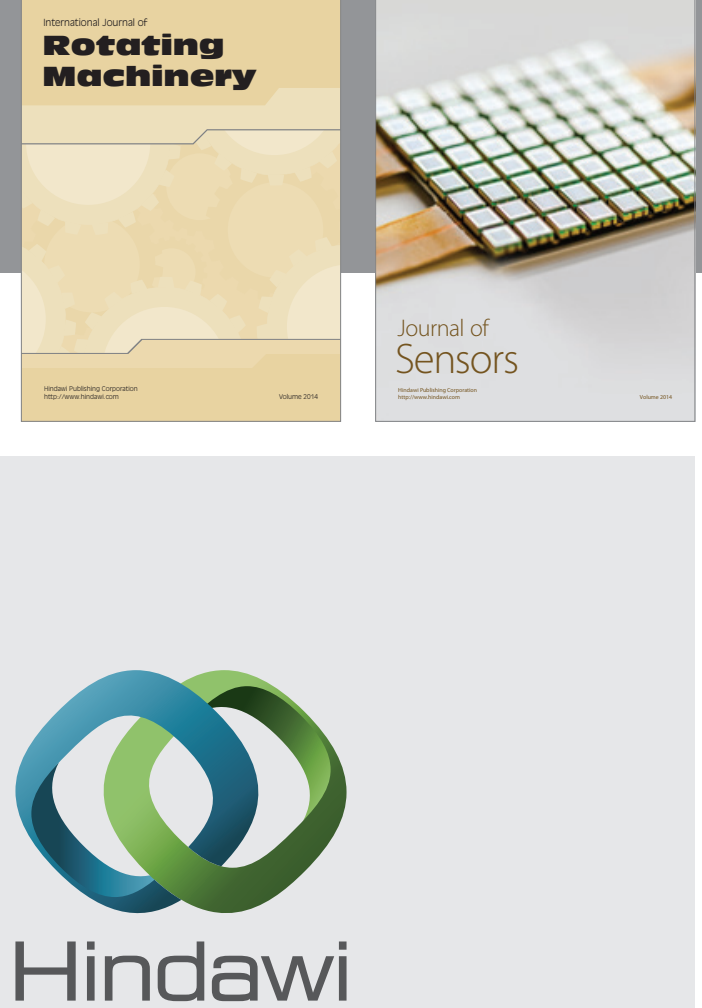

Submit your manuscripts at http://www.hindawi.com
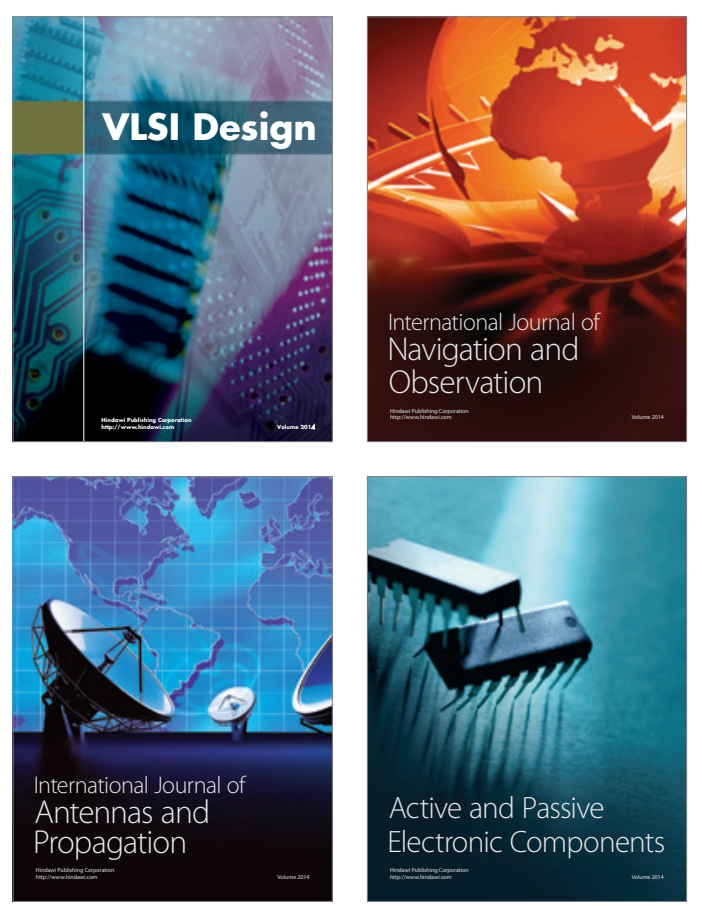
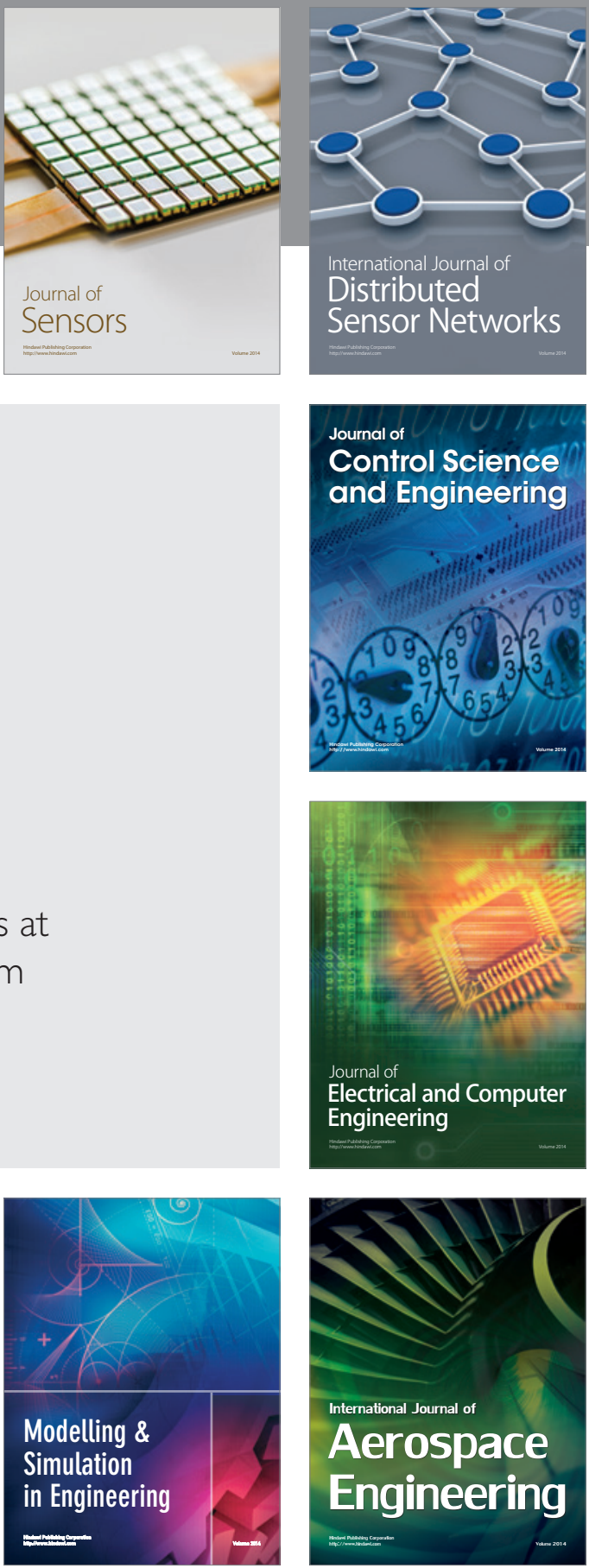

Journal of

Control Science

and Engineering
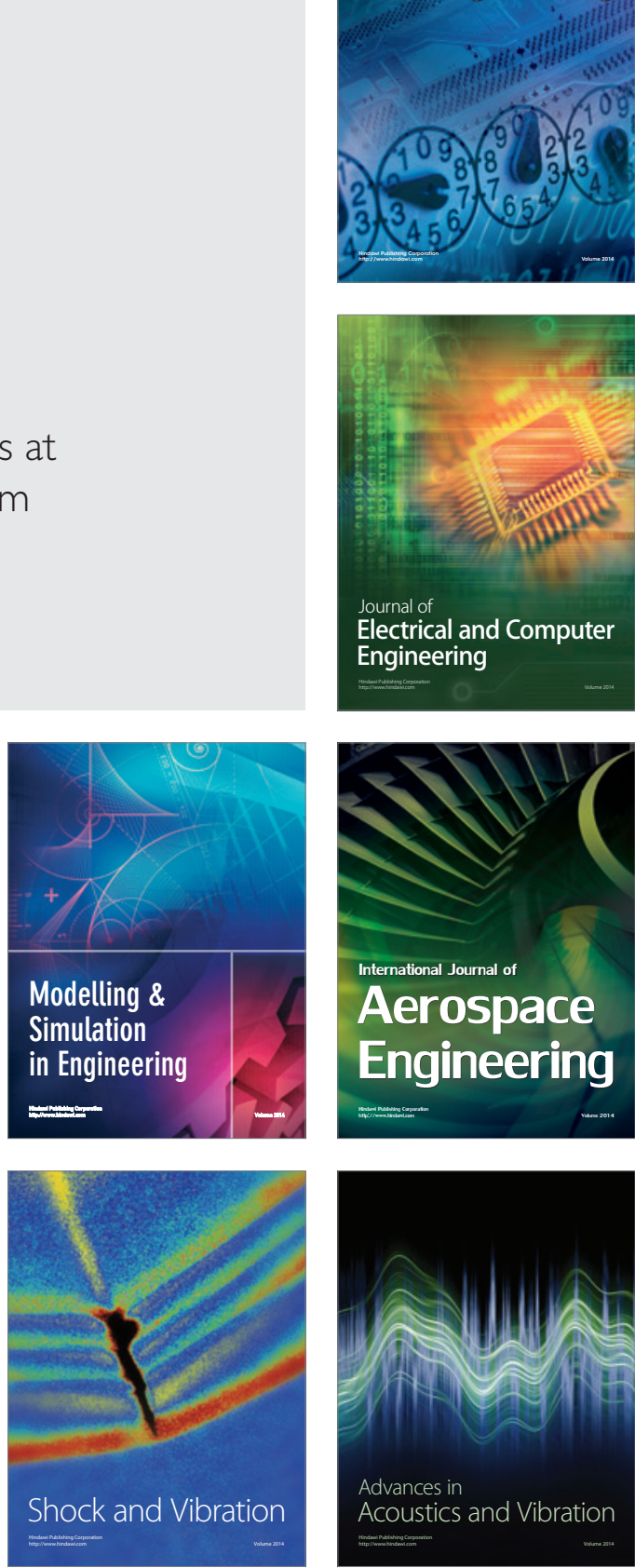